\title{
Studies on Cyclic and Dynamic Loading on Cohesive Soil in Road Engineering
}

\author{
Wojciech Sas ${ }^{1}$, Andrzej Głuchowski ${ }^{2}$, Katarzyna Gabryśs $^{3}$, Emil Soból ${ }^{4}$, Alojzy Szymański ${ }^{5}$ \\ ${ }^{1,3}$ Water Center Laboratory, Faculty of Civil and Environmental Engineering, \\ Warsaw University of Life Sciences - SGGW, Warsaw, Poland \\ 2, 4, 5 Department of Geotechnics, Faculty of Civil and Environmental Engineering, \\ Warsaw University of Life Sciences - SGGW, Warsaw, Poland

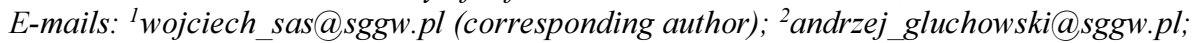 \\ ${ }^{3}$ katarzyna_gabrys@sggw.pl; ${ }^{4}$ emil_sobol@sggw.pl; 5 alojzy_szymanski@sggw.pl
}

\begin{abstract}
Soil investigations concerning cyclic and dynamic loading differ from static analysis. The Problem with the abovementioned loads becomes more important, when cohesive soils are taken into consideration. There are plenty of scientific reports containing the analyses of non-cohesive soil behaviour, yet there is still a lack of similar studies on cohesive soils. Repeated loading and dynamic excitations differ between themselves and parameters which are used to describe those phenomena are not congruent. Road constructors seek new approaches to design methods, which would take into account more types dynamic and cyclic excitations. For a successful utilisation of these occurrences in designing codes, mechanical parameters, such as resilient modulus $\mathrm{Mr}$, shear modulus $\mathrm{G}$ and Poisson ratio $v$ or dumping ratio $\mathrm{D}$, need to be determined. The laboratory tests were conducted on sandy clays, which are a common soil in Poland, using specialized laboratory equipment, such as a resonant column and cyclic triaxial apparatus. The aim of the work presented in this paper was to measureand analyse the abovementioned mechanical characteristics. The paper ends with conclusions regarding the application of cyclic and dynamic loading characteristics in road design.
\end{abstract}

Keywords: dynamic loading, cyclic loading, road constructions, small strains, resilient response.

Conference topic: Soil and rock investigation.

\section{Introduction}

The general division of bituminous roads is based on their main structural elements. The bituminous, rigid and granular layers are constructed, to provide the optimal distribution of traffic loads (Habiballah, Chazallon 2005).

The bearing capacity of a soil included in the unbound granular layer and a subgrade is usually established by conducting the CBR test. When the quality of these two layers is sufficient, then the rutting takes place mainly in granular base and a subgrade layer (Habiballah, Chazallon 2005; Brown 1996).

The long-term cyclic loading and short-term dynamic loading characterises the traffic loading. The long-term loadings, defined as a "quasi-static loading", cause long-term settlements and creep process to occur. The dynamic loadings caused by traffic may also occur in the form of short-term deformation of layers, characterized by the small permanent strain and the behaviour of layer, which may be seen as reversible (Habiballah, Chazallon 2005).

In case of a road constructed on a low embankment based on soft soil, the permanent deformation characteristics caused to traffic become an important factor, which impacts the design life and maintenance of road (Chai, Miura 2002; Sas, Głuchowski 2013).
The design method of road layers thickness can be divided into two categories. The first one is a mechanistic road analysis, which uses the multilayer linear elastic model. The second one is based on a cyclic triaxial test. The laboratory tests conducted on the road layer material can lead to establishing the actual mechanical behaviour of soil under cyclic loading by simulating the insitu conditions (Habiballah, Chazallon 2005; Ghadimi et al. 2015; Bassani et al. 2015).

The calculations of characteristic values for the road design purposes concerns the estimation of the resilient modulus $\mathrm{M}_{\mathrm{r}}$ and characterizing the permanent strain accumulation. The $\mathrm{M}_{\mathrm{r}}$ value is connected with the non-linear elasticity model (Huhtala 2002). The plastic displacement is calculated mostly on the basis of empirical models, based on the results of cyclic triaxial tests, which present the plastic strain function of a number of cycles (Wang et al. 2013).

The response of soil to repeated loading is dependent on the deviator stress value. The low pressure results in small strain and elastic response of the soil. This phenomenon is observed during dynamic tests. Assumptions have been made that the stress-strain characteristic of the small amplitude cyclic loading is purely elastic, provided that the strain amplitude does not exceed $10^{-4} \%$. One of the best methods of obtaining this kind of loading and separating the elastic relation between stress and strain is propagating in the soil the small am-

(C) 2016 The Authors. Published by VGTU Press. This is an open-access article distributed under the terms of the Creative Commons Attribution License, which permits unrestricted use, distribution, and reproduction in any medium, provided the original author and source are credited. 
plitude stress waves (Massarsch 2004). The linear stress-strain curve below the strain level being equal $0.001 \%$ was observed for uncemented granular soils (Atkinson, Sallfors 1991; Lai, Rix 2002).

The small-strain characteristic modulus is called the "maximum Young's modulus $E_{\max }$ " or the "maximum shear modulus $G_{\max }$ ". The $G_{\max }$ value corresponds to the linear elastic region of strain, where no plastic strains occur. If the shear force is high enough, the $G$ value starts to deviate from $G_{\max }$.

In the small-strain, elastic zone the shear modulus is calculated using the Eq. (1):

$$
G=\rho \cdot V_{s}^{2},
$$

in which $\rho$ stands for soil density and $V_{s}$ stands for the shear wave speed. The shear wave speed is estimated, using the Bender Element Test. The bender elements are piezoelectric cantilever strips, which are placed on top of the soil specimen's bottom side. The principle governing the Bender Element Test is based around the motion of the piezoelectric material, which is a part of the bender element equipment. The electric signal produces compressional (P) and shear ( $\mathrm{S}$ ) waves. The wave produced by bender element propagates through the soil sample and induces a voltage in the second bender element, which is placed opposite of the specimen. The wave propagation data recorded by the emitter and receiver of the bender element in function of time leads to estimating the shear and compression wave velocity (Davich et al. 2004).

The repeated loading conditions in which the plastic strain occurs are different from the ones associated with dynamic loading, during which excitations occur in the elastic zone. The most commonly accepted stiffness parameter for characterising the subbase and subgrade materials is the resilient modulus $M_{r}$. It is based on the elastic theory, although subgrade materials themselves are not elastic. If the load is small enough, after a large number of repetitions the soil can behave in an elastic manner, meaning that the deformation is nearly fully recoverable (Huang 2004; Lavasani et al. 2015; Ba et al. 2015). The resilient modulus is a well-known parameter for road design. However, its application is limited to an uniaxial stress state. The phenomenon of plastic deformation decrease during cyclic loading is connected with the shakedown concept, while the state in which no permanent deformation occurs is called the "resilient state". The $M_{r}$ value is calculated using the Eq. (2):

$$
M_{r}=\frac{\sigma_{d}}{\varepsilon_{r}},
$$

in which $\sigma_{d}$ stands for the deviator stress and $\varepsilon_{r}$ stands for the recoverable strain. The resilient modulus value can be obtained by triaxial tests performed in order to designate the resilient modulus of the tested soil. Numerous methods and numerical models have been proposed in order to obtain the $M_{r}$ value (Ba et al. 2012; Hopkins et al. 2007). One of them is the $k-\theta$ mod- el called the "Uzan - Witczak model". It describes the resilient modulus characteristic for varying confining pressure (Uzan 2004).

This model can be used for various types of soil. Its attributes $\left(k_{1}, k_{2}\right.$, and $\left.k_{3}\right)$ for a given soil type remain the same, regardless of the stress state. Furthermore, employing models used to predicting the constitutive model attributes for a given set of soil properties is recommended when attempting to characterize the resilient modulus behaviour, rather than developing models individually for each possible combination of expected stress states. The Uzan-Widczak model equation is presented in the Eq. (3):

$$
M_{r}=k_{1} \cdot P_{a} \cdot\left(\frac{\theta}{P_{a}}\right)^{k_{2}} \cdot\left(\frac{\tau_{o c t}}{P_{a}}\right)^{k_{3}},
$$

in which $\theta$ stands for the bulk stress $\theta=\sigma_{1}+\sigma_{2}+\sigma_{3}$, $P_{a}$ stands for the atmospheric pressure, $\tau_{\text {oct }}$ stands for the octahedral normal stress $\tau_{\text {oct }}=\frac{1}{3} \sqrt{\left(\sigma_{1}-\sigma_{2}\right)^{2}+\left(\sigma_{1}-\sigma_{3}\right)^{2}+\left(\sigma_{2}-\sigma_{3}\right)^{2}}, \quad k_{1}, k_{2}$ and $k_{3}$ are regression constants that are a function of soil properties.

Resilient Modulus value of granular materials is dependent from several parameters, among which the most important are the stress level and moisture content (Hicks, Monismith 1971). Other parameters include compaction and radial stress. The $M_{r}$ value decreases along with the increase in water content.

The difference between elastic moduli in smallstrain and plastic zones is presented in Figure 1. The $E_{\max }$ value is calculated from the $G_{\max }$ parameter. The formula is as follows (4):

$$
E=2 \cdot G \cdot(1+v),
$$

in which $v$ stands for the Poisson ratio.

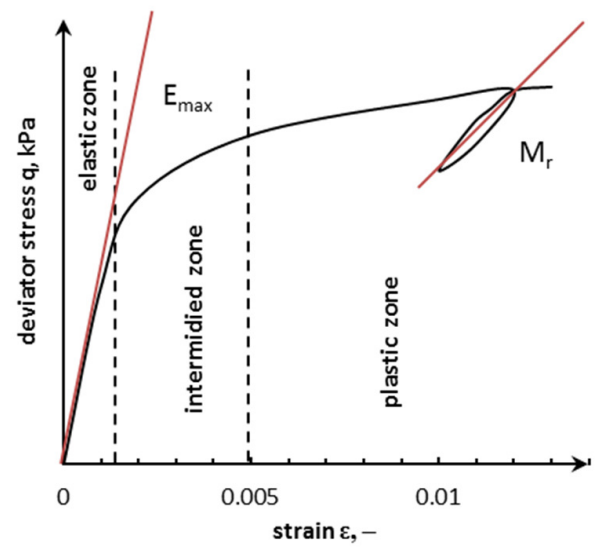

Fig. 1. Diagram of differences between the elastic moduli in a small-strain zone and the resilient modulus in a plastic zone

In this article, the comparison between $E_{\max }$ and $M_{r}$ values was presented. The impact of cyclic loading in plastic zone could lead to an occurrence of the harden- 
ing phenomenon. During the unloading stage, the hysteresis curve is characterised with different resilient modulus value. The elastic response during the first phase of unloading, in which modulus value is greatest, is probably the most interesting aspect. The article investigates the possibility of resilient modulus in small-strain range being similar to the to $E_{\max }$ value. The analysis was conducted following the tests using the cyclic triaxial apparatus and resonant column apparatus with torsional shear equipment. The $E_{\max }$ value can be treated as the maximal material elastic modulus. The shakedown concept explains how the soil may return to a quasi-elastic state. Therefore, characteristic to this state modulus may be equal to $E_{\max }$.

\section{Material and methods}

The tested material was classified as a cohesive soil. It was recognised as a sandy clay $(\mathrm{saCl})$, by performing tests based on sieve and aerometric analysis (Bouyoucos method using a modification made by Casagrande), in accordance with the EUROCODE 7 (PN-EN 146882:2004) standard. Test results are shown in Figure 2.

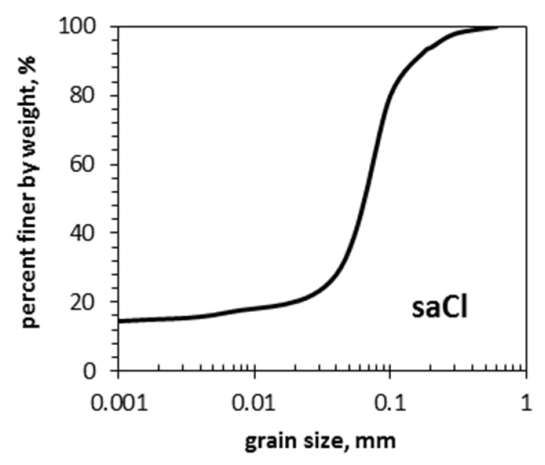

Fig. 2. Particle size distribution of tested soil

The liquid limit test was also performed. On the basis of six sets of tests using the Casagrande apparatus with varying moisture content the liquid limit was established as being equal $18.9 \%$, classifying this soil as a clay with low plasticity.

The optimum moisture content was established by performing the Proctor test. It was achieved by performing a compaction in the Proctor mould whose volume equalled $2.2 \mathrm{dm}^{3}$. Standard energy of compaction, equal to $0.59 \mathrm{~J} / \mathrm{cm}^{2}$, was used. Optimum moisture content for sandy clay was equal $11.2 \%$ and maximum dry density at optimum moisture content reached the value of $2.08 \mathrm{t} / \mathrm{m}^{3}$. Results of the Proctor's test are presented in Figure 3 .

Tests conducted on sandy clay have led to obtaining the data concerning its physical and mechanical properties.

Bender element and resonant column tests lead to the estimation of the shear modulus, Young modulus and finally, the Poisson ratio. Figure 4 presents the results obtained from bender element test for sandy clay.
Table 1 presents the results of physical and mechanical tests conducted on sandy clay.

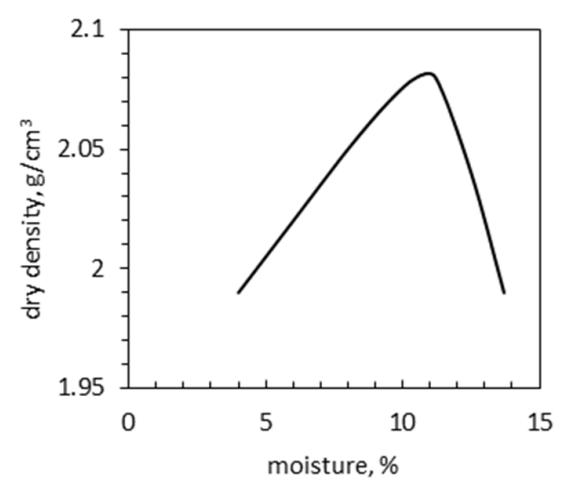

Fig. 3. Particle size distribution of tested soil

Table 1. Physical and mechanical properties of sandy clay in this study

\begin{tabular}{l|c|c}
\hline \multicolumn{1}{c|}{ Properties } & Symbol & Value \\
\hline Skeleton density & $\rho_{s}\left(\mathrm{~g} \cdot \mathrm{m}^{-3}\right)$ & 2.64 \\
Volume density & $\rho_{d}\left(\mathrm{~g} \cdot \mathrm{m}^{-3}\right)$ & 2.08 \\
Natural moisture & $w_{n}(\%)$ & 12.82 \\
Liquid limit & $w_{l}(\%)$ & 18.9 \\
Plasticity limit & $w_{p}(\%)$ & 10.3 \\
Plasticity index & $I_{p}(-)$ & 8.6 \\
Void ratio & $e_{0}(-)$ & 0.41 \\
\hline
\end{tabular}

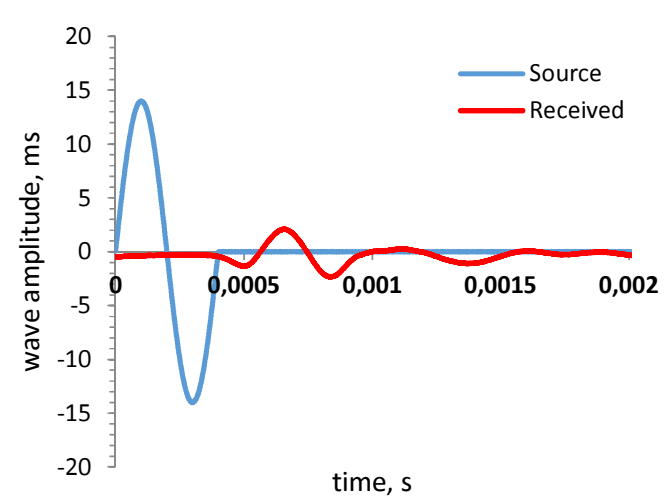

Fig. 4. Result of bender element test for sandy clay

After determining the properties of soil, several series of triaxial tests in cyclic loading conditions were conducted. The tests were performed on compacted soil in accordance with the Proctor method.

The authors ran two kinds of experiments, one using the RCA device and one using the CTRX. However, the tests were conducted with an attempt to maintain similar testing conditions during both measurements. Initial effective confining pressure, for example, was set to be $175 \mathrm{kPa}$ during all of the conducted tests. The examined soils were initially saturated, and the $\mathrm{B}$ values measured in the triaxial specimens exceeded 0.95. Subsequently, the tested specimens were consolidated to the required state of stress. 
The resonant column device successfully used in these studies was manufactured by a British company GDS Instruments Ltd. The GDS RCA has a fixed-free configuration, i.e. the specimen is fixed to the pedestal at the bottom end, and the other end is connected to the drive plate, while the top cap remains free. This system is provided with a testing unit (testing chamber), control computer, back pressure system, cell pressure controller, resonant column controller and a data acquisition box. A more detailed description of the apparatus is contained in the following articles: Sas and Gabryś (2012), Gabryś et al. (2013), Sas et al. (2013).

Right after the first mode is found, the measurements of the resonant frequency $\left(F_{r}\right)$ of the vibration amplitude are made. Subsequently, these measurements are combined with the specimen size and equipment characteristics in order to determine the shear wave velocity $\left(V_{S}\right)$, shear modulus $(G)$ and shearing strain amplitude $(\gamma)$. Based on the elastic wave propagation, the fundamental data-reduction equation Eq. (5) can be established:

$$
\frac{I}{I_{0}}=\left(\frac{\omega_{r} L}{V_{S}}\right) \tan \left(\frac{\omega_{r} L}{V_{S}}\right),
$$

in which $I$ and $I_{0}$ stand for the moments of specimen inertia and the driving system, respectively; $\omega_{r}$ the natural frequency stands for the system and $L$ stands for the length of the sample. In this study, the specimens of a typical size were used, i.e. means $70 \mathrm{~mm}$ in diameter and $140 \mathrm{~mm}$ in height.

Upon calculating the shear wave velocity, the shear modulus could be computed from the Eq. (1).

In cyclic triaxial apparatus samples were consolidated to in-situ stress and vertical effective stress equal to $175 \mathrm{kPa}$, and vertical radial stress ratio was equal 1 . Cyclic stress amplitude was determined, according to the simulation of traffic wave pressure. Cyclic stress frequency was equal $0.1 \mathrm{~Hz}$, in order to simulate moving wheels. The total number of cycles was 100 .

\section{Results}

The triaxial tests were performed in order to, above all, designate the resilient modulus of sandy clay under the changing confining pressure. The second objective of the test was to estimate the maximal value of resilient modulus during the first stage of unloading. The permanent strain accumulation was also noted. The axial strain development during tests conducted in the triaxial test apparatus is presented in Figure 5.

The strain observed during this test indicates three possible ways of soil responding to such loads. The tests were performed under constant radial stress equal to $\sigma_{3}=175 \mathrm{kPa}$. The first one, in which deviator stress amplitude $\mathrm{q}_{\mathrm{a}}$ was equal $5.32 \mathrm{kPa}$ and maximal deviator stress $q_{\max }$ was equal $29.23 \mathrm{kPa}$, resulted in low strain accumulation. The second test was performed under the following conditions: the deviator stress amplitude $q_{a}$ was equal $26.58 \mathrm{kPa}$ and the maximal deviator stress $q_{\max }$ was equal $66.41 \mathrm{kPa}$. The strain accumulation was higher and a growing tendency of strain accumulation can be observed in the logarithmic scale of time on Figure 5 . The last test conducted on sandy clay is characterised by the following values: $q_{a}=51.64 \mathrm{kPa}, q_{\max }=$ $156.94 \mathrm{kPa}$. The strain accumulation displays characteristic growth, which may lead to failure when more cycles in this manner would be applied.

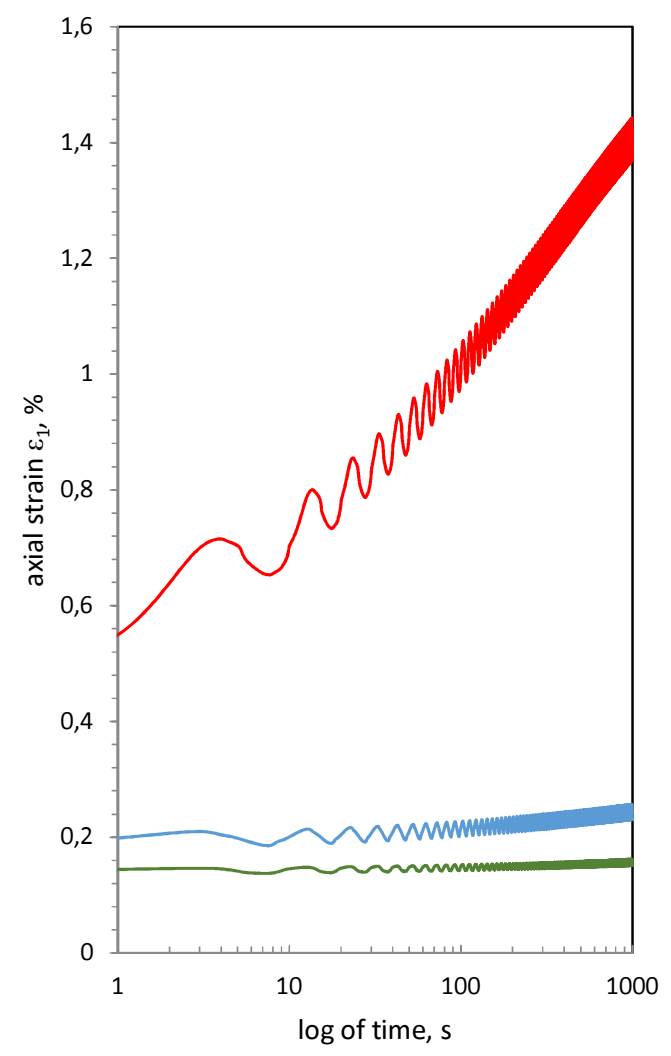

Fig. 5. Axial strain development during cyclic traiaxial test

All three tests present a characteristic way of strain development, which can be classified as abation. This concept is characteristic for the strains which, in logarithmic scale of number of cycles or time, tend to be linear, while the magnitude of irrecoverable strains decreases with each subsequent cycle. The schematic representation of the abovementioned behaviour is presented in Figure 6.

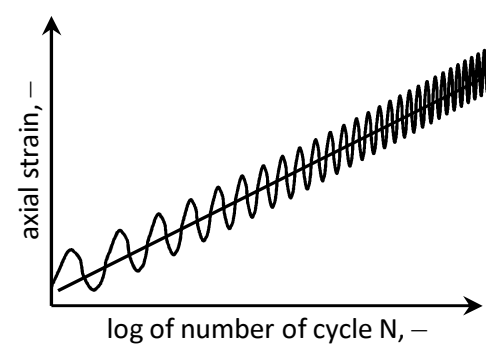

Fig. 6. The schematic representation of strain development 
The recoverable strains characterised by the resilient modulus are presented in Figures 7 to 9. The value of the deviator stress $q$, which was applied during all three tests, is presented by Figure 10 .

The 100-cycle hysteresis loops were analysed and the value of $\mathrm{M}_{\mathrm{r}}$ was established for three tests. The additional value of $M_{r \text { max }}$, which characterizes the modulus with maximal slop on stress-strain plot was also calculated. The purpose of these calculations was to evaluate the correlation between maximal resilient modulus and $E_{\max }$. The resilient modulus had different values for each of the applied deviator stress levels, the $M_{r \max }$ value was also different for each test. This phenomenon is dependent from the deviator stress level. In case of Test 1 , the $M_{r}$ and $m_{r \text { max }}$ values wer equal 48.8 MPa and 107.6 MPa respectively, while for the Test 2 these values reached 100.3 MPa and 115.2 MPa for $\mathrm{M}_{\mathrm{r}}$ and $\mathrm{M}_{\mathrm{r} \max }$ respectively. During Test 3, the $\mathrm{M}_{\mathrm{r}}$ was equal $69.5 \mathrm{MPa}$ and $M_{r \text { max }}$ was equal $113.4 \mathrm{MPa}$.

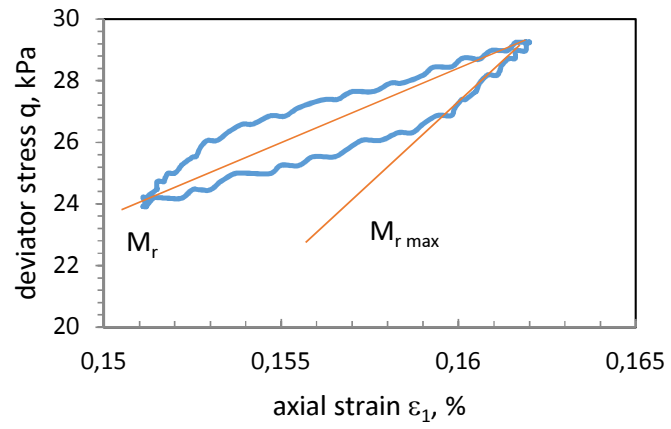

Fig. 7. The hysteresis loop during the $100^{\text {th }}$ cycle of Test 1

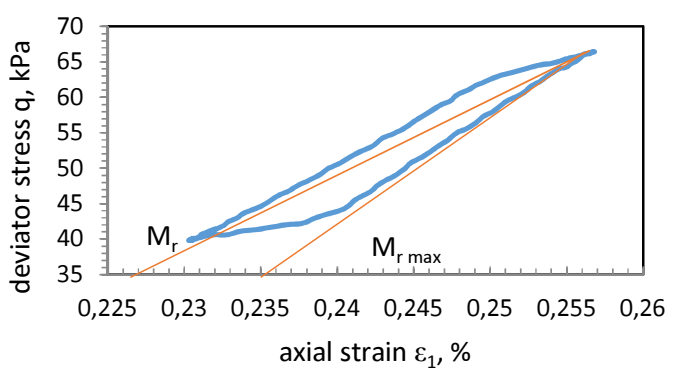

Fig. 8. The hysteresis loop during the $100^{\text {th }}$ cycle of test 2

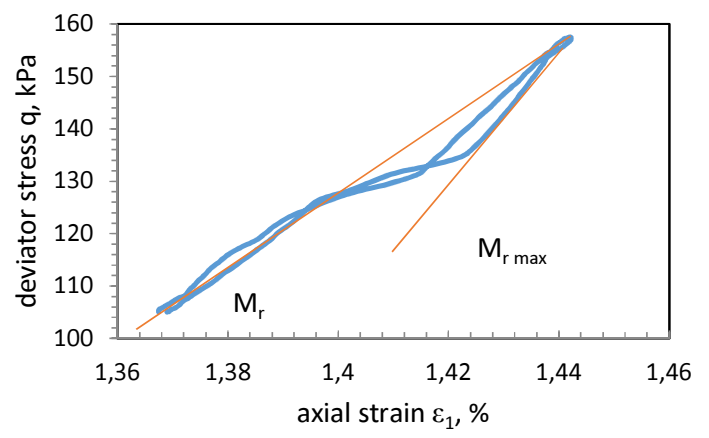

Fig. 9. The hysteresis loop in $100^{\text {th }}$ cycle for test 3

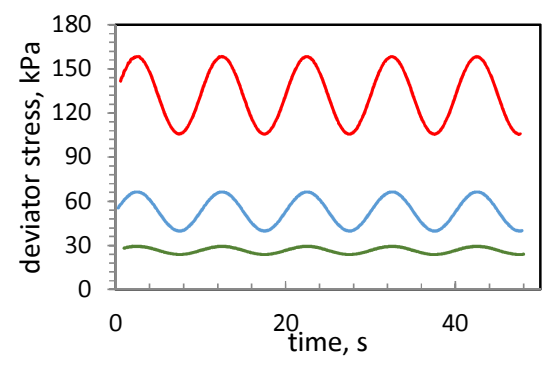

Fig. 10. The stress time plot of cyclic triaxial test setup (green - test 1, blue - test 2, green - test 3 )

The difference between resilient modulus values are clearly caused by the deviator stress value and another parameters which describes amplitude median etc. The parameters of stress are stress amplitude $\left(S_{a}\right)$, maximal stress $\left(S_{\max }\right)$, minimal stress $\left(S_{\min }\right)$, stress median $\left(S_{m}\right)$ and stress difference $(\Delta S)$. The formula for calculation of these parameters is presented by Eqs (6) to (8):

$$
\begin{gathered}
S_{a}=\left(S_{\max }-S_{\min }\right) / 2 ; \\
S_{m}=S_{\max }-S_{a} ; \\
\Delta S=S_{\max }-S_{\min },
\end{gathered}
$$

in which the $S_{\max }$ and the $S_{\min }$ value stand for the maximal and minimal deviator stress during the test. The characteristic deviator stress values are presented in Table 2. The plot of deviator stress $q$ versus effective stress $p$ ' indicates an impact of excessive pore pressure $\Delta u$ on the stress paths (Fig. 11).

Table 2. Characteristic deviator stress $q$ parameters during this study

\begin{tabular}{c|c|c|c}
\hline & 1 & 2 & 3 \\
\hline$S_{\min }$ & 24.20 & 40.12 & 105.66 \\
\hline$S_{\max }$ & 29.26 & 66.17 & 151.26 \\
\hline$S_{a}$ & 2.53 & 13.02 & 22.80 \\
\hline$S_{m}$ & 26.73 & 53.14 & 128.46 \\
\hline$\Delta S$ & 5.05 & 26.04 & 45.60 \\
\hline
\end{tabular}

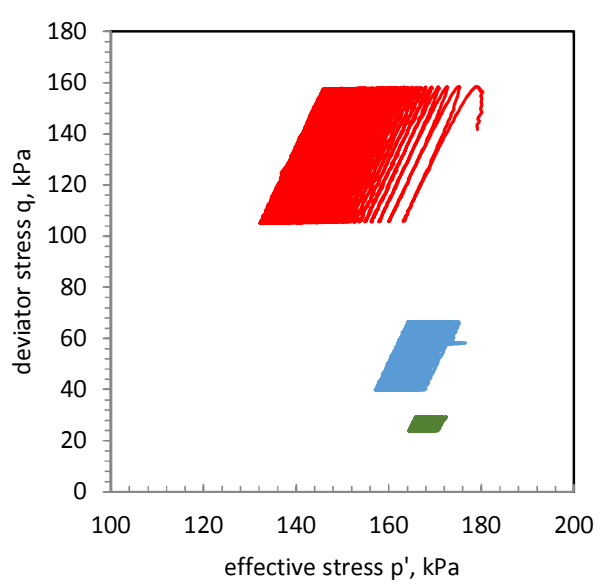

Fig. 11. Deviator stress $p$-effective stress $p$ ' of tested sandy clay samples (green - Test 1 , blue - Test 2 , red - Test 3 ) 
The cyclic loading of soil led to the development of resilient modulus value, during 100 repetitions. The change of $M_{r}$ and $M_{r \text { max }}$ is presented in Figure 12. The $M_{r}$ value change was steady; in consequence no great changes were observed during the cyclic loading. The $M_{r \text { max }}$ value displayed quite different manner of behaviour, as the maximal resilient modulus increase during the initial loading cycles. The highest values for resilient modulus were observed during Test 2 . The lowest $M_{r}$ value was noted for the sample used in Test 1 .

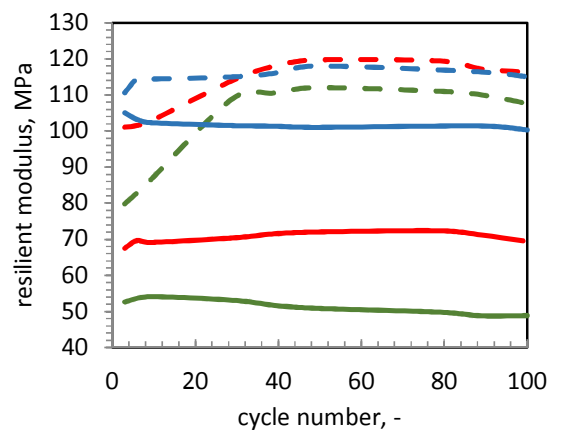

Fig. 12. Deviator stress $p$-effective stress $p$ ' of tested sandy clay samples (green - Test 1 , blue - Test 2 , red - Test 3 )

The conclusion can be drawn, that optimal load conditions exist, under which the $M_{r}$ value reaches the highest level. Under different load conditions, the resilient modulus will be lower.

The dynamic test results are presented in Table 3. The S-wave velocity and P-wave velocity were measured. The results were $262.8 \mathrm{MPa}$ and $1148.3 \mathrm{MPa}$ for $G_{\max }$ and $E_{\max }$ respectively. The $M_{r \max }$ value was almost constant during all three tests. The difference between maximal resilient modulus values is also low. Therefore, the empirical relationship between elastic parameter $-M_{r \text { max }}$ and P-wave velocity can be establish. The relationship is presented in Eq. (9):

$$
M_{r \max }=\frac{V_{P}}{10},
$$

in which $M_{r \text { max }}$ value is expressed $\mathrm{MPa}$ and $V_{P}$ is expressed in $\mathrm{m} \cdot \mathrm{s}^{-1}$.

Table 3. Characteristic deviator stress q parameters during this study

\begin{tabular}{c|c|c}
\hline Properties & Symbol & Value \\
\hline S-wave velocity & $V_{s}\left(\mathrm{~m} \cdot \mathrm{s}^{-1}\right)$ & 262.8 \\
P-wave velocity & $V_{P}\left(\mathrm{~m} \cdot \mathrm{s}^{-1}\right)$ & 1148.3 \\
Shear modulus & $G_{\max }(\mathrm{MPa})$ & 143.6 \\
Young modulus & $E_{\max }(\mathrm{MPa})$ & 422.9 \\
Poisson ratio & $v(-)$ & 0.47 \\
\hline
\end{tabular}

The resilient modulus value change is dependent from the deviator stress magnitude, which described by shakedown theory. The relationship between the characteristic deviator stress q parameters and resilient modulus value is presented in Figure 13.

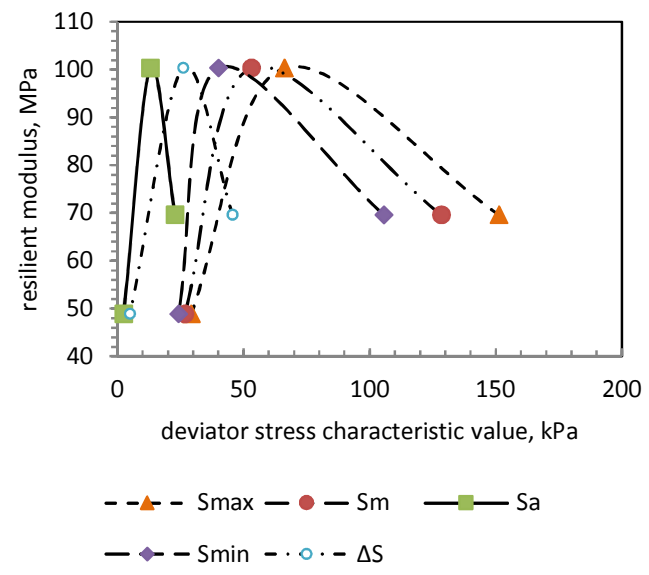

Fig. 13. Plot of resilient modulus change versus characteristic deviator stress parameters

The resilient modulus value is dependent not only from the deviator stress value but also from the amplitude and level of cyclic excitation (stress median). The highest $M_{r}$ value was observed during the second test. The characteristic deviator stress parameters in this study were close to each other. The Eq. (10) correlates the characteristic deviator stress values with resilient modulus change:

$$
M_{r}=G_{\max } \cdot\left(\frac{\Delta S}{S_{m}}+\frac{S_{a}}{S_{m}}\right) .
$$

This empirical formula would be utilized as preliminary resilient modulus value source for cohesive soils, which are cyclically loaded by axial stress with known characteristic parameters of amplitude and median.

The Eq. (10) shows a good correlation when compared to test results. Figure 14 presents comparison of resilient modulus value obtained from tests and Eq. (10) versus the $S_{m}$ value.

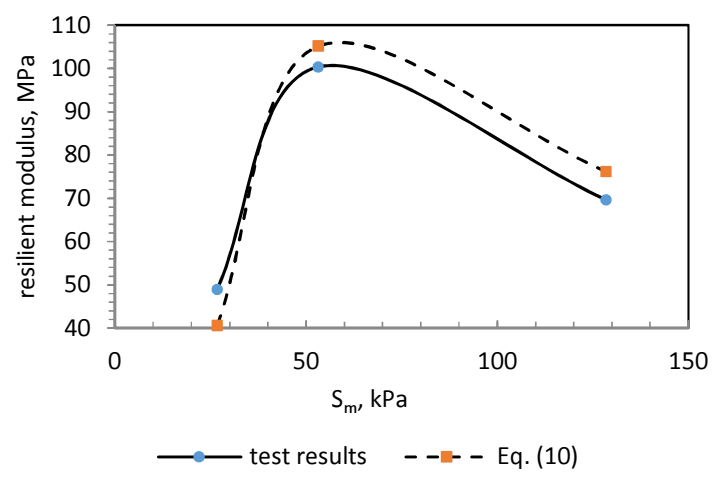

Fig. 14. Plot of resilient modulus change versus the $S_{m}$ value.

The direct comparison of resilient modulus obtained from tests and Eq. (10) is presented in Figure 15. 


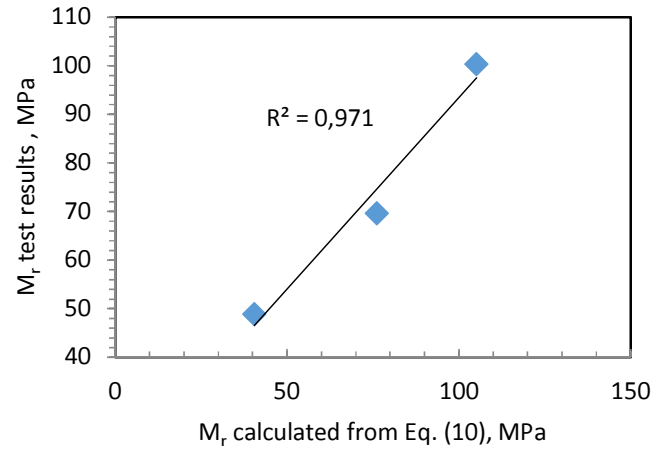

Fig. 15. Plot of resilient modulus change versus $S_{m}$ value

The coefficient of determination $\mathrm{R}^{2}$ for $M_{r}$, obtained during the tests and calculated on the basis of Eq. (10), is equal 0.971 for linear function.

\section{Conclusions}

The geotechnical design of road constructions needs also to take into account the deformation properties of soils. The fundamental geotechnical concepts, like the strain level or deviator stress quantity, should be taken into consideration. The studies on soil dynamics and earthquake engineering made a huge progress. The methods provided by modern test equipment ensure reliable means for determining elastic and deformation properties of soils. The results presented in this paper illustrate some differences between the dynamic and cyclic loading of sandy clay. The test results lead to the following conclusions:

1. The strain observed during this test, indicates three possible ways of soil responding to such loads. In the first one, the deviator stress amplitude level was low, which results in low strain accumulation. In the second response, in which the load conditions were on other level than in first case, the strain accumulation was higher and the growth tendency of strain accumulation can be observed in the logarithmic scale of time. The strain accumulation presents a characteristic growth tendency, which may lead to failure, if more cycles are applied in the third case.

2. The strain development was recognised as abation. The abation concept is characteristic for strains, which tend to be linear in the logarithmic scale versus number of cycles, while the magnitude of irrecoverable strains decreases with each subsequent cycle.

3. The cyclic loading of soil led to a development of resilient modulus value during 100 repetitions. The $M_{r}$ value change was steady; during cyclic loading almost no changes were observed. The $M_{r \max }$ value behaves in a quite different manner, as the maximal resilient modulus increased during the initial loading cycles. The highest values of resilient modulus were observed during Test 2 . The lowest $M_{r}$ was noted for the sample used in Test 1.
4. Results of dynamic tests are presented by $G_{\max }$ and $E_{\max }$ values, based on the $\mathrm{S}$-wave velocity and $\mathrm{P}$-wave velocity measurements. The results are 262.8 MPa and 1148.3 MPa respectively.

5. The $M_{r \max }$ value was constant during all three tests in subsequent cycles of loading. The difference between maximal resilient modulus values was low. The empirical relationship between elastic parameter $-M_{r \text { max }}$ and P-wave velocity was established. This relationship is presented by the Eq. (9).

6. The $M_{r}$ value is dependent not only from the deviator stress, but also from amplitude and level of cyclic excitation (stress median). The highest $M_{r}$ value was observed during the second test. The Eq. (10) correlates the characteristic deviator stress values with resilient modulus change. The Eq. (10) would be utilized as a preliminary resilient modulus value source for cohesive soils, which are cyclically loaded by axial stress with known characteristic parameters of amplitude and median.

7. The coefficient of determination $\mathrm{R}^{2}$ for $M_{r}$ obtained from the tests and calculated on the basis of Eq. (10) is equal 0.971 for linear function.

\section{Disclosure statement}

Authors declare no competing financial, professional, or personal interests from other parties.

\section{References}

Atkinson, J. H.; Sallfors, G. 1991. Exerimental determination of stress-strain-time characteristics in laboratory and in situ tests, in Proceedings of the $X^{\text {th }}$ International Conference on Soil Mechanics and Foundation Engineering, 27-30 May 1991, Florence, Italy, 3: 915-956.

Ba, M.; Fall, M.; Sall, O.; Samb, F. 2012. Effect of compaction moisture content on the resilient modulus of unbound aggregates from Senegal (West Africa), Geomaterials 2(1): 19-23. http://dx.doi.org/10.4236/gm.2012.21003

Ba, M.; Tinjum, J. M.; Fall, M. 2015. Prediction of permanent deformation model parameters of unbound base course aggregates under repeated loading, Road Materials and Pavement Design 16(4): 854-869. http://dx.doi.org/10.1080/14680629.2015.1063534

Bassani, M.; Khosravifar, S.; Goulias, D. G.; Schwartz, C. W. 2015. Long-term resilient and permanent deformation behaviour of Controlled Low-Strength Materials for pavement applications, Transportation Geotechnics 2: 108-118. http://dx.doi.org/10.1016/j.trgeo.2014.12.001

Brown, S. F. 1996. $36^{\text {th }}$ Rankine lecture: soil mechanics in pavement engineering, Geotechnique 46(3): 383-426. http://dx.doi.org/10.1680/geot.1996.46.3.383

Chai, J. C.; Miura, N. 2002. Traffic-load-induced permanent deformation of road on subsoil, Journal of Mechanical and Geoenvironmental Engineering 128(11): 907-916.

http://dx.doi.org/10.1061/(ASCE)1090-0241(2002)128:11(907)

Davich, P.; Labuz, J.; Guzina, B.; Drescher, A. 2004. Small strain and resilient modulus testing of granular soils. A Final Report No. 2004-39. Minnesota Department of Transportation, St. Paul. 
Gabryś, K.; Sas, W.; Szymański, A. 2013. Kolumna rezonansowa jako urządzenie do badań dynamicznych gruntów spoistych [Resonant Column Apparatus as a device for dynamic testing of cohesive soils], Przeglad Naukowy Inżynieria i Ksztaltowanie Środowiska 22(1): 3-15 (in Polish).

Ghadimi, B.; Nega, A.; Nikraz, H. 2015. Simulation of shakedown behavior in pavement's granular layer, International Journal of Engineering and Technology (IJET) 7(4): 198-203. http://dx.doi.org/10.7763/IJET.2015.V7.791

Habiballah, T.; Chazallon, C. 2005. An elastoplastic model based on the shakedown concept for flexible pavements unboung granular materials, International Journal for Numerical and Analytical Methods in Geomechanics 29: 577-596. http://dx.doi.org/10.1002/nag.426

Hicks, R. G.; Monismith, C. L. 1971. Factors influencing the resilient properties of granular materials, Highway Research Record 345: 15-31.

Hopkins, T. C.; Beckham T. L.; Sun, C. 2007. Resilient modulus of compacted crushed stone aggregate bases. Research Report KTC-05-27/SPR-229-01-1F, Kentucky Transportation Center, College of Engineering, University of Kentucky, Lexington.

Huang, Y. H. 2004. Pavement analysis and design. $2^{\text {nd }} e d$. New Jersey: Pearson Prentice Hall.

Huhtala, M. 2002. COST 337 - Unbound granular materials for road pavement, in Proceedings of the $6^{\text {th }}$ international conference on the bearing capacity of roads and airfields, 24-26 June 2002, Lisbon, Portugal.

Lai, C. G.; Rix, G. J. 2002. Solution of the rayleigh eigenproblem in viscoelastic materials, Bulletin of the Seismological Society of America 92(6): 2297-2309.

http://dx.doi.org/10.1785/0120010165
Lavasani, M.; Namin, M. L.; Fartash, H. 2015. Experimental investigation on mineral and organic fibers effect on resilient modulus and dynamic creep of stone matrix asphalt and continuous graded mixtures in three temperature levels, Construction and Building Materials 95: 232-242. http://dx.doi.org/10.1016/j.conbuildmat.2015.07.146

Massarsch, K. R. 2004. Deformation properties of fine-grained soils from seismic tests. Keynote lecture, International Conference on Site Characterization, ISC'2, 19-22 September 2004, Porto, Portugal.

PN-EN ISO 14688-2:2004. Geotechnical investigations - soil classification - part 2: classification rules. Polish Committee for Standardization, Warsaw, Poland, 2004 (in Polish).

Sas, W.; Gabryś, K. 2012. Laboratory measurement of shear stiffness in resonant column apparatus, ACTA Scientarium Polonorum, series Architectura 12(3): 39-50.

Sas, W.; Głuchowski, A. 2013. Effects of stabilization with cement on mechanical properties of cohesive soilsandy-silty clay, Annals of Warsaw University of Life Sciences-SGGW. Land Reclamation 45(2): 193-205.

Sas, W.; Szymański, A.; Gabryś, K. 2013. The behaviour of natural cohesive soils under dynamic excitations, in Proceeding of the $18^{\text {th }}$ International Conference on Soil Mechanics and Geotechnical Engineering, 2-6 September 2013, Paris, France, 2: 1587-1590.

Uzan, J. 2004. Permanent deformation in flexible pavements, Journal of Transportation Engineering 130: 6-13.

http://dx.doi.org/10.1061/(ASCE)0733-947X(2004)130:1(6)

Wang, J.; Guo, L.; Cai, Y.; Xu, C.; Gu, C. 2013. Strain and pore pressure development on soft marine clay in triaxial tests with a large number of cycles, Ocean Engineering 74: 125-132.

http://dx.doi.org/10.1016/j.oceaneng.2013.10.005 